\title{
A Review on the Professional Development of Elementary Education Teachers in China
}

\author{
Ying Luo ${ }^{\mathrm{a}, 1, *}$, Wenbin $\mathrm{Xu}{ }^{\mathrm{b}, 2}$ \\ ${ }^{a}$ Nanjing Normal University, Nanjing 210097, China

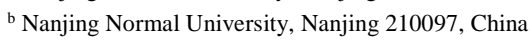 \\ ${ }^{1}$ luoying_8908@sina.com; ${ }^{2}$ mikealxu@ 126.com \\ * corresponding author
}

ARTICLE INFO

Article history

Received 2019-10-12

Revised 2019-11-04

Accepted 2019-11-09

Keywords

School standard

Teacher professional development;

Teachers in China

Education in China

\begin{abstract}
The school field is the main field of teachers' study and work, which creates the field space for teachers' professional development. In order to explore the situation of teacher professional development in school field based on the general condition of the research, from the research scope, the research perspective, the fit between teaching and learning in the research and the discussion that the theoretical research focuses on the value of practice, we have sorted out the hot spots and trends of the research on the professional development of Primary and high school teachers in China from the perspective of school standard. In the subsequent research, we need to make further thinking or exploration in the five aspects of the origin and fulcrum of the research, the positioning of the research, the establishment of the research thinking, the consideration of the influential factors in the research and the enlightenment of the research methodology.
\end{abstract}

\section{Introduction}

The research on teacher professional development has a prominent position in international education research. Chinese researcher research mainly focuses on the connotation of teacher professional development, structure, and promoting way mode, stage, teachers' growth level, also have Chinese researcher pointed out that teachers in the school should take on more important responsibilities, schools should become the important base of teacher's professional development. To do this, we have reviewed relevant literature on the professional development of Chinese primary and high school teachers. It hopes to provide possible directions for the improvement of his research cognition and the expansion of his research scope [1]. School is the main activity field of teacher professional development in primary and secondary schools. School-based research on teacher professional development is also an essential part of the research on teacher professional development. Here we analyze the general situation of the study to present the knowledge picture of the research. The research objects is mainly include journal papers and academic dissertations Master Degree Papers and Doctoral thesis. Figure .1. give an explanation description. 
Fig. 1. Post quantity trend chart

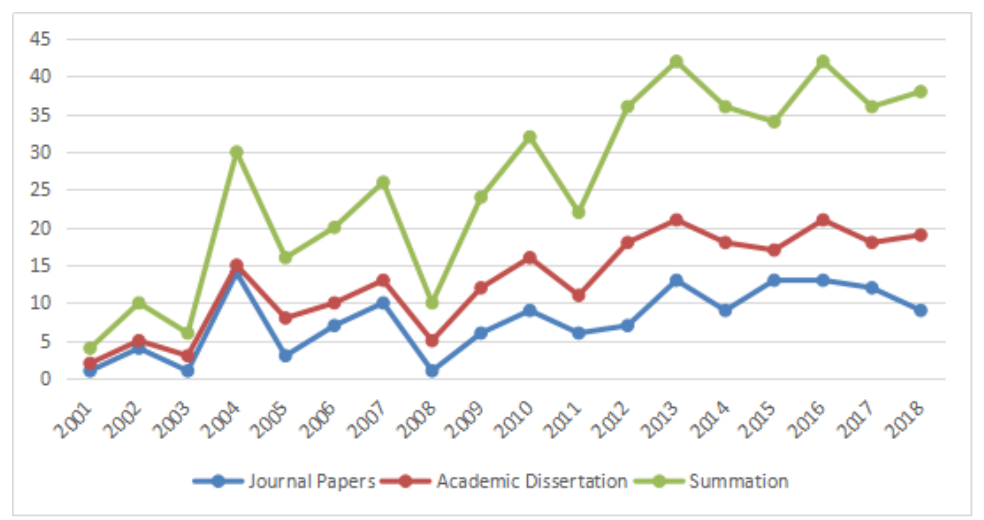

Base on a figure. 1, journal papers is taken as the first object of analysis. Firstly, the timeliness of journal paper research and the pioneering content of research are more significant than those of books. Second, the core ideas of influential works in the research field are generally published in journals. In this study based on CNKI search engine, has carried on the literature search (retrieval condition: subject $=$ school-based teacher professional development or school field under the teachers' professional development or teacher professional development school $=$ core journals + CSSCI source category, = social science disciplines two series, start-stop = year on January 1, 2001 - December 31, 2018), the retrieved 505 journal papers; In the same way, 234 dissertations were retrieved. After reading, the literature materials with weak relevance to the topic and evaluation were eliminated, and 232 research samples were finally obtained. With the above-mentioned retrieved journal papers and academic dissertation as the analysis objects, the following research results were obtained through the literature time-frequency statistics, author background, research methods, and research topic analysis. The number of papers published in the journal generally fluctuates and rises. In 2004 and 2013, there was a small peak of growth, while in 2017 and 2018, there was a slight decline. The development trend of master's degree papers is quite similar to that of journal papers, and the number of published documents reached its peak in 2016. On the whole, the study of school-based teacher professional development twists and turns forward, but the research results are not productive. Table 1. explains the statistical of research topic distribution.

Table 1. Statistical Table of Research Topic Distribution

\begin{tabular}{|c|c|c|c|c|c|}
\hline $\begin{array}{l}\text { Tim } \\
\text { The }\end{array}$ & $\begin{array}{l}\text { Quantum } \\
\text { aper Type }\end{array}$ & $2001-2006$ & $2007-2012$ & 2013-2018 & $\begin{array}{c}\text { Summation } \\
\text { (Article } \\
\text { Number/Percentage) }\end{array}$ \\
\hline \multicolumn{2}{|c|}{ Journal Papers } & 30 & 39 & 69 & $138 / 59$ \\
\hline \multirow{2}{*}{$\begin{array}{l}\text { Academ } \\
\text { ic } \\
\text { Dissert } \\
\text { ation }\end{array}$} & $\begin{array}{l}\text { Master } \\
\text { Degree } \\
\text { Papers }\end{array}$ & 11 & 26 & 32 & $69 / 30$ \\
\hline & $\begin{array}{c}\text { Doctoral } \\
\text { Dissertation }\end{array}$ & 7 & 10 & 8 & $25 / 11$ \\
\hline \multicolumn{2}{|c|}{$\begin{array}{c}\text { Summation } \\
\text { (Article }\end{array}$} & $48 / 21$ & $75 / 32$ & $109 / 47$ & $232 / 100$ \\
\hline
\end{tabular}

According to the inflection point in the development trend graph, the research results are artificially divided into three periods: 2001-2006, 2007-2012 and 2013-2018. From 2001 to 2006, journals showed a slow-growth trend. From 2007 to 2012, the growth of research results was slow; From 2013 to 2018, the increase was relatively flat. There was a research craze in 2013, and the 
attendance dropped slightly after 2013. However, the growth rate of postgraduate and doctoral theses in each period is relatively slow.

According to the selected research samples, the author's background analysis is divided into two parts: the dissertation author analysis and the journal paper author analysis. Generally speaking, East China Normal University and Northeast China Normal University have the highest occurrence rate of dissertation authors. In terms of majors, the ones with the most articles published more than ten times include education management, curriculum and pedagogy, Educational principles, and Comparative education. Of course, there are also some other first-level disciplines of education, such as preschool education, higher education, economic education, and management. It is worth mentioning that in addition to education, there are also students majoring in Chinese language and literature and English.

Table 2. The Author of The Academic Dissertation Attends School Occurrence Frequency Ranking

\begin{tabular}{cccc}
\hline The Sorting & The School & The Earliest Year of Its \\
Appearance
\end{tabular}

According to the authors of journal articles, only one paper was published by 104 authors, accounting for $80.6 \%$ of the total. The other five authors published a total of 16 articles. The researchers were equally represented by front-line teachers and university staff. The proportion of front-line teachers was 51.9 percent. The percentage of faculty members in universities is $48.1 \%$, among which East China Normal University, Beijing Normal University, Southwest University, Chinese University of Hong Kong, and Shanghai Normal university have relatively high frequency. Besides, a large number of university authors are graduate students, as well as professors and associate professors. Based on the above analysis, it is found that scholars from East China Normal University, Beijing Normal University, Northeast Normal university, and Southwest University show high frequency and pay more attention to the research of school-based teacher professional development. However, there are few and scattered authors who study this topic continuously and intensively.

\section{Methods}

Educational research methods mainly include theoretical research, empirical research, and practical research. Among them, empirical research is qualitative research, quantitative research, and comprehensive research. Considering that part of the actual samples could not be classified into the above three research methods, comparative study was added [2]. Table 3. Describes the schoolbased teacher professional development statistics of research methods.

Table 3. School-based teacher professional development statistical table of research methods

\begin{tabular}{|c|c|c|c|c|c|}
\hline \multicolumn{2}{|c|}{$\begin{array}{l}\text { Time } \\
\text { Tuantum } \\
\text { Research } \\
\text { Methods }\end{array}$} & 2001-2006 & 2007-2012 & 2013-2018 & $\begin{array}{c}\text { Summation } \\
\text { (Article } \\
\text { Number/Percentag } \\
\text { e) }\end{array}$ \\
\hline \multicolumn{2}{|c|}{ The Theoretical Study } & 34 & 42 & 37 & $113 / 48$ \\
\hline \multirow{3}{*}{$\begin{array}{c}\text { The } \\
\text { Empirical } \\
\text { Research }\end{array}$} & $\begin{array}{l}\text { Qualitative } \\
\text { Research }\end{array}$ & 2 & 5 & 9 & $16 / 7$ \\
\hline & $\begin{array}{l}\text { Quantitative } \\
\text { Research }\end{array}$ & 4 & 6 & 12 & $22 / 9$ \\
\hline & $\begin{array}{c}\text { Comprehensiv } \\
\text { e Research }\end{array}$ & 8 & 13 & 7 & $28 / 13$ \\
\hline
\end{tabular}




\begin{tabular}{ccccc} 
Practice Research & 6 & 17 & 14 & $37 / 16$ \\
$\begin{array}{c}\text { Comparative Study } \\
\text { Summation }\end{array}$ & 5 & 6 & 5 & $16 / 7$ \\
$\quad$ (Article & $59 / 25$ & $89 / 39$ & $84 / 36$ & $232 / 100.0$ \\
\hline Number/Percentage) & & & & \\
\hline
\end{tabular}

On the whole, theoretical research accounts for the most significant proportion, followed by empirical research, in which comprehensive analysis is more, while qualitative research and quantitative research are less. Finally, practical and comparative research and comparative is the least. From the perspective of the development of the three periods, from 2001 to 2006, the number of actual research and comparative research was relatively small, while the number of theoretical and empirical research was in the majority. From 2007 to 2012, the number of practical studies increased significantly, and the number of academic studies accounted for the majority, while the number of comprehensive studies increased to a certain extent. The number of qualitative and quantitative studies increased from 2013 to 2018, while the number of other research methods declined slightly.

School-based teacher professional development research institute focuses on a wide range of issues, including teacher professional development school, teacher practice reflection, school-based teaching and research, school management, teacher culture, learning community, and professional autonomy. This shows that the research under this topic is continuously expanding its research scope, and the quantity of research is accumulating at the same time, the quality of research is also continually improving. Through the statistics and analysis of the research object, author background, research method, and research topic, the author hopes to further clarify the context of teacher professional development research in the field of school.

\section{Results and Discussion}

Based on the above analysis, the general situation of school-based teacher professional development research is clarified, and further research is expected to present a richer picture.

\section{1) Clarity of research scope}

Relatively mature field research often starts from what and how to understand the problem of the original analysis. China researchers begin to pay close attention to the result of the teachers professional development, namely, teaching knowledge, stick to the teachers beliefs and teaching skills of ascension, to focus on the process of teachers professional development, namely teacher dynamic development process, then turned to pay attention to the purpose of teacher professional development, teacher development consciousness, initiative and encourage teachers to participate in curriculum and teaching reform. As researchers have a deeper understanding of the concept and structure of teacher professional development, their research scope has become clearer [3]. The research scope of school-based teacher professional development mainly includes what is teacher professional development, why to promote teacher professional development, and how to promote teacher professional development. Some researchers discussed this field from the perspectives of ontology, epistemology and methodology, in order to further clarify the research scope [4]. Some researchers also pointed out that the development of the teacher group and individual, the development of connotation, and extension, the study of macro strategy and microsystem in the field of school are all included in the category of analysis. Other researchers indicated that school-based teacher professional development involves three dimensions, namely demand-driven, professional cooperation and support system [5]. Among them, demand drive reveals the internal driving force of teacher development, namely the research should pay attention to the development needs of teachers themselves. Professional cooperation is to promote the generation of teachers' wisdom in the form of peer assistance by improving their situational knowledge and skills. The support system, that is, teacher professional development is a dynamic process. The school needs to establish a set of support systems to ensure the sustainability of this process. In conclusion, researchers have gradually clarified the scope of research from different dimensions, making school-based research on teacher professional development increasingly clear.

\section{2) Diversity of research perspectives}


With the deepening of the research, the perspective of school-based research on teacher professional development shows a trend of diversification. Among them, the philosophical perspective is the universal research paradigm, among which practical knowledge, teacher belief, tacit knowledge, and so on become the high-frequency concepts in his research. In recent years, reflection has also received special attention and become prominent learning in the study of teacher professional development. At the same time, wisdom in philosophy has also become a favorite in the study of teacher professional development. Especially in the era context represented by artificial intelligence, it endows teachers with new connotations, value appeal and methodological significance of professional development. Researchers keep on returning to the original point of reflection and find that method and virtue are the fundamental paths for teachers to become intelligent and intelligent maker. A life philosophy is also increasingly into the field of vision of researchers. A sociological perspective can be said to be an early field of study. Functionalism advocates the passive development paradigm under the regulations of policy and system [6]. On the contrary, the theory of social conflict supports the active development paradigm - debugging conflict and contradiction. Symbolic interaction advocates the influence of significant others .

The study of fairness in critical theory has become a new focus. As a hot topic in recent years, the ecological perspective aims to emphasize the dynamic development of teachers' skills and qualities. The standpoint of pedagogy has formed two research ideas. One is adaptive development theory, that is, teachers' professional development aims at adapting to the requirements of new curriculum reform. The second is interactive development theory, that is, teacher professional development is an important basis of curriculum reform, curriculum reform also has a role in promoting teacher professional development. Due to the complexity and variability of curriculum reform, teachers are no longer bystanders but participants in teaching and curriculum reform, or even the subject of curriculum reform [7]-[10]. in a word, the research in this field shows the overlapping effect of multiple perspectives and disciplines, and the research forms are more systematic and abundant. At the same time, we should realize that the school-based research on teacher professional development is a systematic research based on philosophical speculation [1117]. To recognize its unique complexity and field dependence.It is necessary to realize that its research is not only concerned with the group of teachers, but also with individual teachers.It is necessary to realize that academic research is an integral part and even a key link in the improvement of teachers' quality and even teaching quality. School-based research on teacher professional development has distinct characteristics of times, cultural history and sociality. From the perspective of methodology, the research emphasizes the systematic view, which emphasizes that theory originates from practice and guides practice. It can be seen that philosophy, sociology, pedagogy, ecology, system science and other disciplines are closely related to school-based research on teacher professional development, which provides a rich research perspective for further in-depth discussion.

\section{3) Research focuses on the fit of teacher's teaching and learning}

From the perspective of their existence, the teaching and learning of the teacher subject is not only in itself but also for others, and they gain the significance of teacher development in the sense of interaction, integration, and coupling. The existence of teaching and learning of teachers in teacher professional development is both explicit and practical. Teachers teaching is manifested as intentionality in knowledge, belief, and skills, while teachers' learning is mostly manifested as autonomy and conscious intentionality. Teachers teaching is directly related to their professional development, and teachers learning is, of course, a part of their ability development. The two are equally important. In the past, Chinese researchers mostly considered problems from the perspective of teaching, but in recent years they began to pay attention to the significance and value of learning by teachers. The terminology of teacher learning has evolved from teacher education and teacher training. Some researchers pointed out that learning requires teachers to establish a basic attitude of self-consciousness and autonomy. The ability to teach requires the teacher to have the ability to teach and to follow the trend of thinking. Therefore, the improvement of teaching and learning ability is not natural but requires teachers rational self-consciousness and self-reflection. The research on the subject teaching and learning of teachers is the key issue of teacher professional development. In short, the combination of teaching and learning of teachers in the research on teacher professional development may exert their combined force, especially in the field of school [18]. 


\section{4) The theoretical Research Focuses on The Value of Practice}

There are an unbridgeable space and time boundary between the truth of theoretical research and the reality of practice. If both of them are brought into the orbit of the teaching quality of necessity and the improvement of teachers' quality, it is easy to realize the fit between them. Chinese researchers from the abstract theoretical level of school-based professional development of teachers connotation, theoretical basis, mode (paradigm), development trend, mechanism, and strategy of indepth discussion, but also thinking about the practice of transformation and penetration. For example, some researchers said that school-based teaching and research should be regarded as an important basis for the combination of theory and practice, and should play a positive interaction between the two. Also, the study of teacher culture can trigger philosophical thinking and provide direction for the construction of teacher development environment in the school field. Or the teacher professional development theory and curriculum reform-related thinking, to theory and reform practice of mutual penetration. The work of researchers mostly focuses on the introduction of foreign research theories and experiences, which is generally consistent with the International perspective. International experience is a double-edged sword, which brings vitality and vitality of development but also brings challenges to the development of local behavior. How to seek its development in opportunities and challenges needs to resort to the practice of local action. In a word, school-based research on teacher professional development continues to advance after the new curriculum reform in China, and it has been promoted in such aspects as teacher professional development schools, school linkage paradigm, school-based transformation and curriculum development perspective.

School-based teacher professional development has its internal law, is a system engineering, has the system itself self-organization, adaptability, and level of the characteristics. Therefore, the research on this topic also needs to be integrated thinking, which includes the research scope, research perspective, teachers' teaching, and learning problems as well as practical problems.

\section{5) Research origin Fulcrum -- Theory Blend}

From philosophy theory, sociology theory, education theory to ecology theory, and system science theory, the theoretical basis of school-based teacher professional development research keeps changing. In the process of change, we also need to seek the invariable or original fulcrum in the study of teacher development educating oneself and educating others. There are different opinions on educating others. educating others is often associated with educating oneself, just as good scholars teach themselves, good teachers teach themselves. However, educating oneself and educating others are not created out of thin air. We can resort to the three levels of truth, goodness and beauty. First of all from the true level, if the teacher professional development to review related issues from the perspective of system science, the teacher professional development is a nonlinear dynamic process, will be subject to the system itself from the organizational change and improvement (self), level (Pre-job and post-job, internal and external, macro, medium and micro synergies) and adaptability (adaptation between different groups and individuals). Secondly, from the perspective of goodness, if we think about it with humanistic theory, the research process cannot be separated from human beings, that is, human behaviors and interpersonal relations. People's independence, innovation and self-consciousness should be integrated into the study of teacher professional development. Teachers first need to be independent, which is the basis of their survival, and other goals and ideals are only mirrors.Teachers need to be self-renewing. When we are faced with a group of students full of vitality, we need to get rid of the shackles of solidifying ourselves and hold an immature attitude to face and update ourselves. Teachers should be self-conscious, and the core of self-consciousness is self-study and self-reflection ability. From the perspective of life philosophy, teachers should be self-conscious. Finally, from the perspective of beauty, the problem of teacher professional development can be investigated from the perspective of interpretation and understanding, that is, the influence of hermeneutics theory on its research [19] -[24]. I can plan my career development according to my understanding of teaching and learning, and establish dialogues and understandings with colleagues and students to optimize my teaching process. The essence of the living world and learning world we face is continuous encounters, which are arranged and set. Only when we actively welcome encounters and move towards dialogue and understanding can we not be bothered by encounters [25]. In a word, if school-based teacher professional development 
research reaches the original fulcrum of educating others and educating oneself, the integration of theories of various disciplines may be the key to its continuous development.

6) The Orientation of Research -- the Way of Research in Space-Time Under the Specific Field

The field is defined by sociologist Bourdieu as a specific configuration or network of relationships between positions. [26] It is the existence of the correlation between social conditions and action subjects. Bourdieu also pointed out that society is made up of many small worlds, among which there are internal logic and inevitability to form different field space. Although they are regulated by social rules, they cannot avoid the field limitation of the small world, so this is the part that it exists autonomously. The field of teacher professional development can be carried out from the multiple space-time of International perspective, local behavior, and local as, especially the research on teacher professional development under local as school standard is both theory and practice. However, most of the practical research focuses on theoretical issues. Although the research on practical issues has attracted more and more attention from researchers, the research system is not strong, and the research depth and level need to be improved. Therefore, the theory of teacher professional development research is indispensable, and practical considerations are also important. In a word, it integrates different fields, and space-time conforms to theory and practice and generates a diversified and multi-dimensional research horizon. At the same time, the purpose of the research on teacher professional development is for the professional growth of teachers, the improvement of teaching level and the self-improvement of personality. However, researchers have found that the professional development of school-based teachers is confronted with some difficulties in the real world. The importance of tool rationality leads to the concealment of professional ethics. In the past, theory and practice gradually separated because of the concealment and absence of teachers' subjectivity and the alienation of communication and dialogue between subjects. Of course, school-based research on teacher professional development is not perfect. No research can be applied to all scenarios (fields) and suitable for every teacher, and not all teachers should become expert teachers.

\section{7) Establishment of Research thinking -- Multi-Dimensional System Integration}

The problems encountered in the research are not isolated from each other, but interact with each other and change dynamically, especially in the specific space-time field scene. Systematic research thinking, like a multi-prism, can help researchers to view each part of the system as a whole, as well as the relationship between each element, and analyze the possible future development. Because school-based teacher professional development is a multi-dimensional integration system, that is, an integration system composed of many feedback loops that influence each other, such as teacher belief, ability, and knowledge. By realizing the multi-dimensional integration of their thinking, researchers can grasp the dynamic process of the integration of school-based teacher professional development. [27] With the periodical change of teacher professional development and the change of specific space and time fields, the internal structure will be adjusted accordingly. The selforganizing characteristics of the system itself constantly shape its structure, generate new and diversified structures, and make its overall construction more perfect. If the level of the system can be reasonably designed and its adaptability can be improved in the specific space-time field, the overall system of teacher professional development can be in a virtuous circle. At present, some researchers have constructed the support system of teacher professional development in different environments and different dimensions and preliminarily realized the support of external system and the construction of internal biochemical system. In the future, the integration of exogenous and endogenous systems should be further deepened.

8) Consideration of Influencing Factors -- Seeking Balance between Conflicts and Contradictions

Teacher professional development is a dynamic system engineering, with the characteristics of symmetry among various factors, such as: external and internal; Statute and self-consciousness; Dominance and recessive; Justice and prejudice. These symmetry factors tend to come in pairs, interact and interfere with each other, where the conflict may be fundamental. Of course, the conflict here is not only destructive, but also constructive. When the professional development of teachers in the field of school is only regulated under the policy and management system, it may become a burden for teachers and gradually become an appendage of the system. If policies and systems, as a kind of guidance, are easily transformed into a self-conscious being, they may exert their constructive power. In short, the consideration of symmetry factors in the study of teacher 
professional development is not to avoid conflicts, but to face up to them, embrace them and seek balance.

9) Enlightenment of methodology --dwelling - intimate knowledge

The way of Live-acquaintance comes from Polanyi's metaphor of dwelling. Acquaintance is obtained through the researcher's participation and knowledge, which is inseparable from Live.The way of Live-acquaintance to teacher professional development research mainly includes four meanings: one is that researchers' understanding is mainly based on the school field they live in and the details of their development; Second, they realize that the professional development of teachers in the school field depends on the auxiliary consciousness of the body, that is, the mind resides in the body, and the body plays an instrumental role in the perception of external objects. At the same time, they realize that the self is an active researcher through the perception of the body and the existence of the self-consciousness of action. Third, the traditional Live of teacher professional development, which is the condensation of experience, is a powerful rational tool for researchers to understand and understand schools, and also the basic premise for their research. The fourth is to get acquaintance through Live, to understand the whole picture of teacher professional development in the field of school, in order to make some predictions for the development of school. For researchers and observers of teacher professional development, their methodological inspiration is to intervene deeply in the school field studied in this way. Of course, researchers need to obtain the consent of the school to obtain the whole picture and relevant details of teacher professional development.

The perspective of school-based research on teacher professional development tends to be diversified, and the research content is more abundant. For example, seeking the source and fulcrum of teacher professional development research; Based on the specific field of space-time research road; Seeking multi-dimensional integration of research thinking; Consideration of influencing factors; With the aid of Live-acquaintance. The reasonable analysis of teacher professional development in the dynamic changing school field is in line with the current research reality .

As the main place for teachers' practice activities, the school has the advantage of understanding the needs of teachers' group and individual development and has accumulated rich experience in promoting the improvement of teachers' quality. [28-36]Teachers are not only the main cultural subject in this field but also the important force in the reconstruction of school field. Whether it is the theory or practice of teacher professional development, teachers' self-consciousness is the primary existence. Behind teacher professional development and quality improvement, there may be a hypothesis about human nature; that is, teachers are culturally conscious. This assumption of human nature is the premise for teachers to realize their sustainable development.[37-41]

\section{Conclusion}

Since the new curriculum reform in China, more and more researchers have begun to pay attention to school-based teacher professional development, which is an important basis for their research. At the same time, under the guarantee of the above objective conditions, Chinese researchers may also give in-depth consideration to the following issues. First, Research origin Fulcrum Blend theory. Second, the orientation of research the way of research in space-time under the specific field. Third, establishment of research thinking multidimensional system integration. Four, consideration of influencing factors seeking balance between conflicts and contradictions. And five, enlightenment of methodology dwelling intimate knowledge.

\section{References}

[1] Hu Huimin, Moving towards school-based teacher professional development: problems and ideas, Open Education research.,vol.3,no.2,pp.51-55,2007.

[2] Liu Lianghua, Education research methods 2nd edition, Shanghai: East China Normal University Press.,vol.3,no.2,pp.5,2017.

[3] Zhu Xudong, ZhOU Jun, Review of research on teacher professional development, Chinese Journal of Education.,vol.1,no.3,pp.68-73,2007. 
[4] Ke Zheng, The foundation of professional development of school-based teachers, Global Education Outlook .,vol.40,no.9,pp.37-43,2011.

[5] HU fang, Cultural rationality and teacher development: cultural consciousness of teachers in school-based teaching and research, Southwest university.,vol.1,no.3,pp.23,2013.

[6] YE Lan, Preliminary study on educational research methods, Shanghai: Shanghai Education Press.,vol.1,no.3,pp.3,2014.

[7] Yongjun $\mathrm{Wu}$, Review on the process of teacher professionalization in mainland China, Education Development Research.,vol.1,no.8,pp.43-47,2007.

[8] Qiliang Yang, Several levels of professional development of teachers, Educational Development Research.,vol.24,no.29,pp.54-58,2009.

[9] Gang Ding, Lianjun Chen, Miru Sun, Investigation on the professional development of primary and high school teachers in China, Education Research,,vol.32,no.3,pp.3-12,2011.

[10] Xin Yi, Being a teacher is no longer an iron rice bowl, Education Research.,vol.9,no.3,pp.4,2012.

[11] Cui Yun huo, School-based teacher professional development: the framework and its significance, Journal of Education Development Research.,vol.1,no.8,pp.67-72,2011.

[12] Hua Zhang, On the essence and value orientation of teacher development, Education Development Research.,vol,33,no.22,pp.16-24,2014.

[13] Yunguo Cui,Shao Wang, Professional development of non-teachers is the improvement of professional practice, Education Research.,vol.9,no.3,pp.77-82,2014.

[14] Yibing Liu, Guanghuai Fu. System and mechanism innovation of integrated development of teacher education , Education Research.,vol.35,no.1,111-116.pp.,2012.

[15] Rumi Li, Excellent teachers should follow the path of independent development, Jiang Su Education.,vol.11,no.1,pp.4,2015.

[16] Ping Zhao, Research on teacher professional development system: school teaching and research group -discussion based on three theoretical perspectives ,Education researchvol.1,no.1,pp.37,2017.

[17]Zhu Xudong. The oretical model construction of teacher professional development, Education Research.,vol.35,no.6,pp.81-90,2014.

[18] Sun Ling, Learn to teach to learn , based on the perspective of new teachers' professional development, Journal of Basic Education Course. ,vol.1,no.2,pp. 43-49, 2018.

[19] Xiangming Chen, Practical knowledge: the knowledge foundation of teacher professional developmen, Education Review of Peking University.,vol.1,no.1,pp. 104-112, 2003.

[20] Yonghe zhu, Teacher belief system and teacher professional developmen, Journal of Huzhou Normal University.,vol.3,no.2,pp. 47-50, 2004.

[21] Yong Jiang, On personal knowledge of teachers: a new turn of teacher professional developmen , Educational Theory and Practice.,vol.4,no.6,pp. 56-60, 2018.

[22] Jianling Liu, Pursuit of excellence: a life view of teacher professional development [J]. Curriculum. Teaching Materials, Teaching method.,vol.1,no.1,pp. 67-73, 2005.

[23] Lijuan Pang ,Xiaoyu Han, Construction of rural compulsory education teachers in China: problems and solutions, Education Research.,vol.1,no.9,pp. 47-53, 2006.

[24] PENG Liang, Xu Wenbin, Why children are more difficult to teach -- rethinking and establishing the standpoint of humanistic pedagogy, Education Research.,vol.3,no.37,pp.18-24,2016.

[25] PENG Liang, Xu Wenbin, Review and reflection on teaching design research in the perspective of educational technology (1979-2015), China Audio-visual Education.,vol.12,no.3,pp.101-107,2016.

[26] Pierre.Bourdieu, Practice and reflection -- a guide to reflective sociology, Beijing: Central Compilation and Publication.,vol.1,pp.133-134,1998. 
[27] Zhou Jianhua, Research on professional development of school-based teachers, Education Research and Experiment.,vol.1,no.4,pp.15-21,2014.

[28] Qu Baokui, New progress in education research in China.2004, Shanghai: East China Normal University Press .,vol.2,pp.375-379, 2006.

[29] Longmei Liu, Research on ecological environment and optimization of teacher professional development in special post, Southwest University.,vol.1,no.1,pp.3, 2016.

[30] Xiaoqi Zhang, Policy research on teacher professional development under the beginning plan of America, Central China Normal University.,vol.1,no.1,pp.3, 2016.

[31] Guofei Liu, Research on teacher evaluation based on teacher professional development, Tianjin Normal University .,vol.1,no.1,pp.135-136, 2017.

[32] Yufan Niu, On institutionalized authority of teachers, Henan Normal University,vol.34,no.1,pp.98, 2017.

[33] Runtong Wang, Research on professional development of teachers in transitional universities from the perspective of system innovation, Shenyang Normal University.,vol.7,no.1,pp.21, 2018.

[34] Zhangyun Li, Psychological research on compulsory education teachers' dissatisfaction with performance pay, Nanjing Normal University. ,vol.5,no.1,pp.54-56, 2018.

[35] Dongjiao Huo, A study on the changes of the century-old normal education system in Chin, Northeast Normal University.,vol.3,no.1,pp.31-39, 2018.

[36] Yueling Lv, Research on the status quo and optimization of the honor system for rural teachers in China, Chongqing Normal University.,vol.3,no.2,pp.11-12, 2006.

[37] Max Van Manen, Teaching tact: the implication of educational wisdom, Beijing: Education Science Press.,vol.2,pp.37,2001.

[38] Xinyun Yue, The highest state of teacher development: teachers' life consciousness, Journal of east China Normal University (education science edition).,vol.36,no.2,pp.117-122, 2018.

[39] Ting Yang, Zhe Jin. From passive training to self-conscious training: 40 years of teacher professional development in teaching reform, Global Education Outlook.,vol.47,no.8,pp.25-36, 2006.

[40]Dinghua Wang, Situation and task of teacher team construction in China in the new era, Education Research.,vol.39,no.3,pp.4-11, 2018.

[41] Yuan Xun, Qiaofeng Zeng. Review and reflection on the change of teacher education policy in the past 40 years of reform and opening up -- exploration and practice of two paths of teacher education professionalization, Research on teacher development.,vol.2,no.4,pp.10-16, 2018. 